\title{
Characteristics of emergency department utilization in the U.S.A. and the U.K.: a comparison of two teaching hospitals
}

\author{
D. A. RUND, J. A. NEMER, M. MOESCHBERGER, C. \\ ROBERTSON \& M. GARRAWAY \\ Department of Emergency Medicine, The Ohio State University, Columbus, Ohio, The \\ Royal Infirmary of Edinburgh and the Department of Community Medicine, Edinburgh \\ University.
}

\section{INTRODUCTION}

Appropriate patient use of the accident and emergency (A\&E) department hoss been a subject of concern in the medical literature of both the United Kingdo and the United States for years. Over a century ago the Lancet (1869) publishedo series of reports on outpatient visits in London hospitals. Citing the 'large numbers of apparently trivial cases' seen in out-patient departments, the authors urged curtailment of services. In more recent years, both Fry (1960) and Crombie (1959) concluded that a majority of patients attending their respective $A \& E$ departments $\overrightarrow{0}$ in the U.K. had conditions that could have been managed by a general practitioner. In the U.K., both the Platt Report (1962) and the Expenditure Committee on Accidento and Emergency Services (1974) recommended that non-urgent cases should first seek care from their general practitioner (G.P.), not the A\&E department.

In the U.S.A., the literature of the $70^{\prime}$ 's estimated that between half and twothirds of patient visits were 'for routine primary health care'. (Gibson, 1978). In 1980 Gifford et al. reported the results of a survey of emergency department (ED) physicians in 24 hospitals. The assessment indicated that at least $33 \%$ of theo patients could have safely waited over $12 \mathrm{~h}$ for care. A recent report indicated that $\rightarrow$ $25 \%$ of patients in one E.D. used the department for routine care. Eighty-three per? cent of such patients had public and/or self-pay insurance status (Pane et al., 1991).

Despite some apparent similarities of non-urgent use patterns of emergency స్心 facilities in the U.K. and the U.S.A., we suspected that close inspection mighto reveal important differences in each patient population. The countries have quiteo different systems of medical care reimbursement for physicians and hospitals,

Correspondence: Colin Robertson, Department of Accident and Emergency Medicine, The Royal Infirmary of $\overrightarrow{\bar{D}}$ Edinburgh, Lauriston Place, Edinburgh. 
and both social and cultural differences might affect both patient characteristics and patterns of use.

\section{MATERIALS AND METHODS}

Patients attending the A\&E Departments of two large teaching hospitals were systematically selected and interviewed according to a structured format. The hospitals, the Royal Infirmary of Edinburgh (U.K.) and The Ohio State University Hospital ([O.S.U.] Columbus, Ohio U.S.A.) are affiliated with major medical schools and located in communities remarkably similar in size, economy and governmental activity. The annual patient census for the A\&E Department of the Royal Infirmary $(80000)$ is approximately twice that of the ED at Ohio State $(40000)$.

As a part of the National Health Service, The Royal Infirmary's mission is to provide emergency care to those who require it. The mission is to be met despite limitations of financial resources. The mission of The Ohio State University Hospital is to provide emergency care for all who request it, but in contrast, the financial resources available to the hospital depend in large measure upon reimbursement from patients or third parties for clinical care.

Approximately $20 \%$ of such patients, however, provide no reimbursement at all for care. As is the case in private U.S.A. hospitals, therefore, The Ohio State University Hospitals attempt to develop services that will attract patients who can provide reimbursement for care, while continuing to provide emergency care for all who present for such care regardless of the apparent urgency, the nature of the complaint, or the possibility of payment.

The triage system at each institution separates urgent from non-urgent patients in different ways. In Edinburgh, non-urgent patients are assigned to the 'exam' or 'cubicle' area. In Columbus, non-urgent patients are assigned a three or four (non-urgent) rating at triage and assigned to one of several care areas (surgical, medical, psychiatric, etc.). Every other patient assigned to the non-urgent (cubicle) area of the Royal Infirmary's A\&ËDepartment was selected for interview; every patient presenting to the O.S.U.E.D. with a non-urgent triage score (three or four) was interviewed. Interviewed patients in Scotland totalled 332; and in the U.S.A. totalled 378. Patients excluded from study included those under 18, and those refusing to participate or unable to communicate effectively. The interview was administered by one of the authors (D.A.R.) and senior registrars in Edinburgh and by a medical student interviewer (J.A.N.) in the U.S.A.. All patient charts and questionnaires were reviewed by one of the authors (D.A.R.) to determine completeness and uniformity.

The interviewers inquired about demographic variables, reasons for seeking emergency care at this particular time, duration of illness, previous attempts to seek care elsewhere, perceived availability and appropriateness of alternate care, previous A\&E Department visits, hospitalizations and current medications. The core of the interview was a questionnaire containing explicit questions such as, 'Were you referred here today by your G.P.?'. An estimation of urgency of the condition by both patient and physician was determined with both linear analogue 
scale and time parameters, a technique employed in a previous study of the Royab Infirmary A\&E Department reported by Fitzgerald et al. (1986). To ensure uniformity of urgency rating, all ratings were assigned or reassigned by one physician from? data in the patients's chart.

To ensure a sample of patients representing all time periods for one full week,? sampling frames of $4 \mathrm{~h}$ duration representing all time periods were used in both studies. The interviews took place from March to June 1987 in the Royal Infirmary and from March to May 1988 at Ohio State.

\section{RESULTS}

There were no statistical differences between age groups in the U.S.A. and Scotland, however, males clearly out-numbered females in the Scottish population andfemales out-numbered males in the U.S.A. population (Table 1). The number of unmarried patients in the U.S.A. population was substantially larger than in the Scottish population, reflecting larger groups of both unmarried and separated $\bar{z}_{\bar{z}}$ divorced people in the U.S.A. patient group. Trauma-related injury constituteda the predominant reason for seeking emergency care in the U.K. while illness? predominated as the major complaint in the U.S.A. (Table 2). When the presenting condition is analysed according to sex, females presented more than twice as oftencw with illness than with injury in the U.S.A. In Scotland, females were five times likely to present with injury than illness. Scottish men were six times as likefys to complain of injury than illness. in the United States, the proportion of meno presenting with injury equalled those presenting with illness (Tables $3 \& 4$ ).

Table 1. Comparison of A\&E Department utilization in the United States with the United Kingdom by sex $(P<0.0001)$

\begin{tabular}{cccc}
\hline Sex & Male & Female & Total \\
\hline USA \# & 182 & 198 & 380 \\
$\%$ & 47.9 & 52.1 & \\
UK \# & 208 & 128 & 336 \\
$\%$ & 61.9 & 38.1 & \\
\hline
\end{tabular}

Table 2. Injury vs. illness as presenting emergency complaint $(P<0.0001)$

\begin{tabular}{llc}
\hline & U.S.A. & Scotland \\
\hline Injury & 152 & 282 \\
& $(40 \%)$ & $(85 \%)$ \\
Illness & 226 & 50 \\
& $(60 \%)$ & $(15 \%)$ \\
\hline
\end{tabular}


Table 3. Injury vs. illness as presenting complaint in males

\begin{tabular}{lcc}
\hline Males & U.S.A. & Scotland \\
\hline \multirow{2}{*}{ Injury } & 90 & 178 \\
& $(50 \%)$ & $(86 \%)$ \\
Illness & 91 & 29 \\
& $(50 \%)$ & $(14 \%)$ \\
\hline
\end{tabular}

Table 4. Injury vs. illness as presenting complaint in females

\begin{tabular}{lcc}
\hline Females & U.S.A. & Scotland \\
\hline Injury & 62 & 104 \\
& $(31 \%)$ & $(83 \%)$ \\
Illness & 135 & 21 \\
& $(69 \%)$ & $(17 \%)$ \\
\hline
\end{tabular}

The lapse of time between the onset of symptoms from illness or from the onset of the traumatic event in cases of injury was significantly shorter in Scotland than in the U.S.A. as shown in Table 5. In Scotland three-quarters of patients had symptoms lasting less than $24 \mathrm{~h}$, while in the United States slightly over half had symptoms lasting less than $24 \mathrm{~h}$.

The patients's own perception of the severity of the presenting symptoms and a doctor's perception of severity were each ranked on a one to ten analogue scale. The mean value for the patients's perception was significantly higher in the U.S.A. when compared to the mean value in the Scottish population; however, the doctor's assessment was significantly higher for the Scottish population when compared to the U.S.A. population (Table 6). In both groups injury severity scores were higher for the comparatively small numbers of patients referred to the emergency department by a doctor (Table 7).

One feature that distinguishes the Scottish population from the U.S.A. popu-

Table 5. Duration of symptoms responsible for emergency visit among the U.S.A. and Scottish populations $(P<0.0001)$

\begin{tabular}{lrr}
\hline $\begin{array}{l}\text { Duration of } \\
\text { symptoms }\end{array}$ & \multicolumn{2}{c}{$\begin{array}{c}\text { Number of patients (\% of } \\
\text { each country total) } \\
\text { Scotland }\end{array}$} \\
\hline $\begin{array}{l}\text { Less than } 6 \mathrm{~h} \\
6-24 \mathrm{~h}\end{array}$ & $118(31 \%)$ & $158(48 \%)$ \\
$24 \mathrm{~h}-1$ week & $81(21 \%)$ & $85(26 \%)$ \\
1 week-1 month & $126(34 \%)$ & $56(17 \%)$ \\
Over 1 month & $38(10 \%)$ & $22(6 \%)$ \\
\hline
\end{tabular}


Table 6. Perceptions of severity rated by the patient and by a doctor on a 1 to 10 scale. ${ }^{*} P<0.0001,{ }^{* *} P<0.05$

\begin{tabular}{lc}
\hline Patient perception & Physician assessment \\
\hline U.S.A. $-5.97^{*}$ & $3.22^{* *}$ \\
U.K. $-4.48^{*}$ & $3.46^{* *}$ \\
\hline
\end{tabular}

Table 7. Number of patients referred for emergency care by a doctor with mean urgency ratings for each group (in parentheses). $P<0.0001$

\begin{tabular}{lcc}
\hline & U.S.A. & Scotland \\
\hline G.P. referral & 67 & 74 \\
No G.P. & $(3.99)$ & $(3.57)$ \\
Referral & 311 & 258 \\
& $(3.05)$ & $(3.43)$ \\
\hline
\end{tabular}

lation is the extent to which patients in Edinburgh sought advice from others as justification for making a visit to the A\&E Department before actually presenting $\vec{\bullet}$ for care (Table 8). Patients in Scotland were twice as likely to have sought advioeec from others about the decision to seek care in the A\&E Department than in the U.S.A.. Sources of such advice included spouse, another relative, co-worker, supe visor, teacher or police officer. Some patients made as many as three contactso with others seeking justification for attending the A\&E Department in Scotland. In many cases, at least one of the contacts was a non-physician health professional $\stackrel{\circ}{\rightarrow}$ (e.g., pharmacist or nurse). Such attempts were made with less frequency and응 intensity in the U.S.A..

As might be expected by anyone familiar with health care structures in the U.S.A. and the U.K., patients in Scotland could identify their G.P. significantly more often than could patients in the U.S.A. (Table 9). Married persons in the U.S.A. were twice as likely to know their G.P. than unmarried patients, but there was no such difference observed among the Scottish population. Self-referredo patients were one half as likely to know their G.P. than those referred by someone

Table 8. Numbers and percentages of patients seeking advice from others before seeking emergency care $(P<0.0001)$

\begin{tabular}{lcccc}
\hline & $\begin{array}{c}\text { Advice } \\
\text { from others }\end{array}$ & $\begin{array}{c}\text { No } \\
\text { advice }\end{array}$ & Total \\
\hline U.S.A. \# & 243 & 137 & 380 \\
& $\%$ & 64 & 36 & 100 \\
U.K. & $\#$ & 264 & 74 & 336 \\
& $\%$ & 79 & 21 & 100 \\
\hline
\end{tabular}


else. In general, female patients from both countries were two and a half times more likely to know their G.P. than males.

\section{DISCUSSION}

Emergency centres in the U.K. and the U.S.A. and other countries (Magnusson, 1980; Kooiman et al., 1989) have reported use of A\&E as a primary source of medical care. Pane et al. (1991) in the U.S.A. linked such use to inability to pay private providers, while Shesser et al. (1991) reported that use of the ED for minor care is more related to convenience, the absence of previous provider relationships and inability to make a prompt appointment with their provider. He reported no difference in minor care vs. urgent care patient groups based on racial, educational or economic backgrounds. Part of the difference in these results may relate to the location and nature of each institution.

In the U.K. virtually all patients have an assigned G.P. who is expected to provide care $24 \mathrm{~h}$ a day. It is considered customary, however to bypass the G.P. for the immediate treatment of injury associated with accidents. The opinion that 'illness is for the doctor, accidents are for the hospital' seems to be a widely accepted cultural expectation in the U.K. (Holohan, 1975) and our data seems consistent with such a concept.

In contrast to patients in Edinburgh, patients in the U.S.A. seem to use the E.D. as a source of care for a wide variety of illnesses including psychiatric, gynecologic, obstetric and routine paediatric care. With rather fixed appropriation for the provision of $A \& E$ care the U.K., providers are rightly concerned about the proportion of patients who could be treated by the G.P. In the U.S.A., however, many EDs support the cost of emergency readiness for all by providing on-demand care for those who can pay. The policies of the American College of Emergency Physicians (1982) have consistently stated that the ED should be available for conditions perceived by the patient to require urgent and unscheduled medical attention and in its recently published long range plan states that 'quality emergency care is a fundamental right and should be available to all who seek it (American College of Emergency Physicians, 1990). Such statements emerge from the conviction that American national health policies must deal with the problem of unreimbursed emergency care in U.S.A. hospitals.

One could speculate that reasons for the differences in patient characteristics result from the relative paucity of primary care physicians in the U.S.A. and the difficulty of providing such care in private offices for minor illnesses of those who cannot pay. Another speculation is that EDs in the U.S.A. would not wish to redirect 'paying' patients even if other sources of care were available and thus welcome and sometimes even advertise to attract such patients. We suspect, however, that in addition there are culturally based differences in Scotland in expectations for A\&E care.

Nevertheless, the underlying causes of relatively high demand for non-urgent care in emergency facilities are different in the U.K. than in the U.S.A. This suggests that correction of such use patterns may require different kinds of solution. 
An alternate conclusion might be that certain patients in both countries always prefer immediate hospital-based care for conditions perceived by the patient to be in need of acute care. If such is the case, health systems in both countries should always include provisions for providing such care in planning for future needs.

\section{REFERENCES}

American College of Emergency Physicians (1990) Long range plan and environmental assessment 1990-91: ACEP statement of direction: Value statements, Dallas, American College of Emergency Physicians, approved, board of directors (March 10).

Central Health Services Council (1962) Accident and Emergency Services, HMSO, London.

Crombie D. L. (1959) A Casualty Survey, Journal of the College of General Practice 2, 346-356.

Executive Summary and Comments (1982) Adopted by the Board of Directors, American College of Emergency Physicians (October 23).

Fitzgerald D. J. (1986) The urgency distribution of an accident and emergency department's workload. Archives of Emergency Medicine 3, 225-230.

Fourth Report from the Expenditure Committee for the Session 1973-74, HMSO, London.

Fry L. (1960) Casualties and Casuals. Lancet 1, 163-166.

Gibson G. (1978) Patterns and trends of utilizations of emergency medical services In: G. R. Schwartz (Ed) Principles and Practice of Emergency Medicine, pp. 1513-1518. W.B. Saunders Co., New York.

Gifford M. J., Franizek J. B. \& Gibson G. (1980) Emergency physician's and patient's assessments: urgency of need for medical care. Annals of Emergency Medicine 9 (10), 502-507.

Holohan A. M. (1975) Practitioners, patients and the accident department. The Hospital and Heal通 Services Revieze 71, 80-84.

Kooiman G. G., Van De Wetering B. J. M. \& Van De Mast R. C. (1989) Clinical and demographie characteristics of emergency department patients in the Netherlands; a review of the literature and a preliminary Study, American Journal of Emergency Medicine 7 (6), 622-638.

The Lancet investigation into the administration of the out patient department of the London hospitals; Royal Free Hospital (1869) Lancet, November 13, 677-678.

Magnusson G. (1980) The Hospital emergency department as the primary source of medical care. Scandinavian Journal of Social Medicine 8, 149-156.

Pane G. A., Farner M. D. \& Sainess U. A. (1991) Health care access problems of medically indigent emergency department walk-in patients. Annals of Emergency Medicine 20 (7), 730-733.

Shesser R., Kirsch T., Smith J. \& Kirsch R. (1991) An analysis of emergency department use by patients with minor illness. Annals of Entergency Medicine 20 (7), 743-747. 